\title{
Characterization of Erythromycin and Tetracycline Resistance in Lactobacillus fermentum Strains
}

\author{
Elizaveta Anisimova $(D)$ and Dina Yarullina \\ Department of Microbiology, Kazan Federal University, Kremlevskaya Str. 18, Kazan 420008, Russia \\ Correspondence should be addressed to Dina Yarullina; kasfes@gmail.com
}

Received 4 July 2018; Revised 10 October 2018; Accepted 17 October 2018; Published 11 November 2018

Academic Editor: Clemencia Chaves-López

Copyright (C) 2018 Elizaveta Anisimova and Dina Yarullina. This is an open access article distributed under the Creative Commons Attribution License, which permits unrestricted use, distribution, and reproduction in any medium, provided the original work is properly cited.

Lactobacillus fermentum colonizing gastrointestinal and urogenital tracts of humans and animals is widely used in manufacturing of fermented products and as probiotics. These bacteria may function as vehicles of antibiotic resistance genes, which can be transferred to pathogenic bacteria. Therefore, monitoring and control of transmissible antibiotic resistance determinants in these microorganisms is necessary to approve their safety status. The aim of this study was to characterize erythromycin and tetracycline resistance of $L$. fermentum isolates and to estimate the potential transfer of resistance genes from lactobacilli to the other Grampositive and Gram-negative bacteria. Among six L. fermentum strains isolated from human feces and commercial dairy products, five strains demonstrated phenotypic resistance to tetracycline. PCR screening for antibiotic resistance determinants revealed plasmid-located tetracycline resistance genes tet $(\mathrm{K})$ and tet $(\mathrm{M})$ in all strains and erythromycin resistance genes erm $(\mathrm{B})$ in the chromosome of L. fermentum 5-1 and erm (C) in the plasmid of L. fermentum 3-4. All tested lactobacilli lacked conjugative transposon Tn916 and were not able to transfer tetracycline resistance genes to Staphylococcus aureus, Staphylococcus epidermidis, Listeria monocytogenes, Acinetobacter baumannii, Citrobacter freundii, and Escherichia coli by filter mating. Staphylococcus haemolyticus did not accept erythromycin resistance genes from corresponding Lactobacillus strains. Thus, in the present study, $L$. fermentum was not implicated in the spread of erythromycin and tetracycline resistance, but still these strains pose the threat to the environment and human health because they harbored erythromycin and tetracycline resistance genes in their plasmids and therefore should not be used in foods and probiotics.

\section{Introduction}

Lactobacillus fermentum is a common inhabitant of human gastrointestinal and urogenital tracts where these bacteria are known to exert health-promoting effects $[1,2]$. It is naturally present in raw milk, dairy products, and many traditional fermented foods and beverages [3,4]. Some probiotic isolates, such as L. fermentum RC-14 and L. fermentum 90 TC-4, are already widely used and produced on an industrial scale $[5,6]$. The species is listed in the qualified presumption of safety (QPS) published by the European Food Safety Authority (EFSA) [7], and along with other lactic acid bacteria (LAB), it has been generally recognized as safe (GRAS status) by the U.S. Food and Drug Administration. However, over the last decade, bacteria used as probiotics or in starter cultures have received growing attention with regard to their potential involvement in acquisition and transfer of antibiotic resistance genes to food or gut pathogens $[8,9]$.

In line with the growing awareness of LAB involvement in the spread of antibiotic resistance, it is imperative that the antibiotic resistance profile of probiotic and starter cultures should be studied both at the physiological level and molecular level. A phenotypically resistant strain may be genotypically "susceptible," and in contrast, a susceptible phenotype may carry silent genes, which are observed with genotyping [10]. Determination of antibiotic resistance among lactobacilli is confounded by the absence of standards for susceptibility testing. Microbiological breakpoints have been determined only for some antibiotics and for 
particular most commonly used probiotic species [11]. Besides, minimum inhibitory concentration (MIC) breakpoint values can vary depending on the method and media applied, as well as between species of the same genus [12-14].

Bacterial resistance to antibiotics can be of two types: intrinsic resistance, which is a natural property of an organism, having a minimal potential for horizontal spread and posing no risk in nonpathogenic bacteria, and acquired resistance, which results from mutation or, what is more often, via the acquisition of generic materials, such as a plasmid or a transposon [10]. Lactobacilli have been reported to have a high natural resistance to vancomycin, aminoglycosides, and the majority of nucleic acid inhibitors [15]. Resistance to other antibiotics varies greatly among species. Erythromycin resistance and tetracycline resistance have been found to be acquired, and therefore, corresponding genetic determinants are often considered potentially transferable $[16,17]$. Acquired resistance to erythromycin encoded by the erm(B) gene has been detected in two L. fermentum strains NWL24 and NWL26 isolated from Chinese fermented foods (yogurt) [18]. L. fermentum CB101 also isolated from Chinese fermented food (cucumbers) showed resistance to both erythromycin and tetracycline with very high MICs $(512 \mu \mathrm{g} / \mathrm{ml}$ for erythromycin and more than $128 \mu \mathrm{g} / \mathrm{ml}$ for tetracycline) [19]. From four erythromycin- and tetracycline-resistant $L$. fermentum strains isolated from Indian fermented foods, three strains have been found to harbor the erm(B) gene and one harbors the tetracycline efflux genes tet $(\mathrm{K})$ and tet (L) [20]. Several plasmids potentially implemented in transfer of antibiotic resistance have been identified in $L$. fermentum, e.g., resistance plasmid pLME300 of L. fermentum ROT1 [21], tetracycline and erythromycin resistance plasmids of L. fermentum LF601 [22], and plasmid pLEM3 conferring erythromycin resistance of L. fermentum [23]. The works demonstrating conjugative transfer of antibiotic resistance determinants from lactobacilli to other bacteria especially those belonging to the gut microbiota are very limited [24-26]. So far, there is only one evidence of successful transfer of the erm(B) gene from $L$. fermentum NWL24 to Enterococcus faecalis 181 in filter mating experiments [18].

The aim of this work was to comprehensively characterize erythromycin and tetracycline resistance profiles of $L$. fermentum strains and evaluate the transferability of corresponding resistance genes to other bacteria. In this study, six $L$. fermentum strains isolated from human feces and commercial dairy products were assayed for susceptibility to erythromycin and tetracycline by the agar disc diffusion method, followed by determination of MICs for these antibiotics by the broth microdilution method. Phenotypic assays of bacterial strains were complemented by direct screening for the presence of erythromycin and tetracycline resistance determinants by PCR amplification. The transferability of these antibiotic resistance genes from $L$. fermentum strains to a number of Gram-positive and Gramnegative bacteria was studied in filter mating experiments. This study provides a reference for the safety assessment and contributes to the evaluation system of probiotics.

\section{Materials and Methods}

2.1. Isolation of Bacteria and Growth Conditions. Six Lactobacillus strains were isolated from the feces of healthy individuals (HF-A1, HF-A4, and HF-B1) and commercial dairy products $(3-4,5-1$, and $5-2)$ by serial dilution of the sample in sterile phosphate-buffered saline (PBS), subsequent plating onto the de Man-Rogosa-Sharpe (MRS) agar (HiMedia, India), and incubation under anaerobic conditions (Anaerogas pack; NIKI MLT, Russia) at $37^{\circ} \mathrm{C}$. Single colonies were selected, purified, and maintained on the MRS agar for immediate use and in $20 \%$ glycerol for storage at $-80^{\circ} \mathrm{C}$. Prior to all experiments, bacterial isolates were subcultured at least twice.

2.2. Identification of Bacteria. The bacterial colonies were assigned to the genus Lactobacillus by MALDI-TOF mass spectrometry (Bruker Biotyper system, Bruker Daltonics, Germany), as previously described [27]. In brief, a single fresh colony from the MRS agar was smeared onto a ground steel target (Bruker Daltonik), overlaid with $1 \mu \mathrm{l}$ of a saturated solution of alpha-cyano-4-hydroxycinnamic acid matrix in 50\% acetonitrile and $2.5 \%$ trifluoroacetic acid, and air-dried at room temperature. For each strain, two preparations of the colony material were analyzed. Mass spectra were recorded according to the manufacturer's instructions. The obtained spectra were compared with reference spectra in the integrated database (version 3.2.1.1). Standard Bruker interpretative criteria were applied. Scores $\geq 2.3$ were accepted for reliable species assignment and scores $\geq 2.0$ but $<2.3$ for reliable identification to the genus level. Scores below 2.0 were considered unreliable.

For most accurate species identification, the 16S rRNA gene was amplified by the PCR method using universal $16 \mathrm{~S}$ rRNA bacterial primers $27 \mathrm{~F}$ and 1392R (Table 1) and PCR program described below. The PCR-amplified $1.4 \mathrm{kbp}$ DNA fragments were resolved by agarose gel electrophoresis, purified, and sequenced on an ABI Prism 3730 sequencer (Applied Biosystems). The bacterial isolates were identified to the species level by comparing their 16S rRNA gene sequences with those in the NCBI databases by BLAST.

\subsection{Antibiotic Susceptibility Testing and MIC Determination.} Susceptibility to erythromycin and tetracycline was determined by the disc diffusion method, as described earlier [27]. In brief, bacteria were grown in the MRS broth overnight at $37^{\circ} \mathrm{C}$ in anaerobic conditions (Anaerogas pack; NIKI MLT, Russia) and pour-plated on MRS agar plates (0.5 McFarland after inoculation). Antibiotic discs (Scientific Research Centre of Pharmacotherapy, Russia) were placed on the surface of inoculated plates. After $48 \mathrm{~h}$ incubation in anaerobic conditions at $37^{\circ} \mathrm{C}$, the diameter of the inhibition zone was measured and interpreted as susceptible (S), moderately susceptible (MS), or resistant (R) according to the method in [27]. The following standards for interpreting the zones of inhibition for antibiotics were used: bacteria were considered resistant (R) to erythromycin $(15 \mu \mathrm{g} /$ disc $)$ when the zone of inhibition $(\mathrm{mm})$ was $\leq 10$, moderately susceptible (MS) at 
TABle 1: Primers used in PCR amplifications.

\begin{tabular}{|c|c|c|c|c|}
\hline Target gene & Primer sequence $\left(5^{\prime}-3^{\prime}\right)$ & $T_{\mathrm{a}}\left({ }^{\circ} \mathrm{C}\right)$ & Amplicon size (bp) & Reference \\
\hline $\operatorname{erm}(\mathrm{A})$ & $\begin{array}{l}\text { F: AAGCGGTAAACCCCTCTGAG } \\
\text { R: TCAAAGCCTGTCGGAATTGG }\end{array}$ & 52 & 441 & {$[28]$} \\
\hline \multirow{2}{*}{$\operatorname{erm}(\mathrm{B})$} & $\begin{array}{l}\text { ermB1-F: CATTTAACGACGAAACTGGC } \\
\text { ermB1-R: GGAACATCTGTGGTATGGCG }\end{array}$ & 60 & 425 & {$[28]$} \\
\hline & $\begin{array}{l}\text { ermB2-F: GAAAAGGTACTCAACCAAATA } \\
\text { ermB2-R: AGTAACGGTACTTAAATTGTTTAC }\end{array}$ & 59 & 639 & [29] \\
\hline $\operatorname{erm}(\mathrm{C})$ & $\begin{array}{l}\text { F: ATCTTTGAAATCGGCTCAGG } \\
\text { R: CAAACCCGTATTCCACGATT }\end{array}$ & 49 & 295 & {$[28]$} \\
\hline $\operatorname{erm}(\mathrm{T})$ & $\begin{array}{l}\text { F: TATTATTGAGATTGGTTCAGGG } \\
\text { R: GGATGAAAGTATTCTCTAGGGATTT }\end{array}$ & 55 & 395 & {$[28]$} \\
\hline$m e f(\mathrm{~A})$ & $\begin{array}{l}\text { F: CTATGACAGCCTCAATGCG } \\
\text { R: ACCGATTCTATCAGCAAAG }\end{array}$ & 52 & 1400 & {$[30]$} \\
\hline Int & $\begin{array}{l}\text { F: GCGTGATTGTATCTCACT } \\
\text { R: GACGCTCCTGTTGCTTCT }\end{array}$ & 50 & 1028 & {$[31]$} \\
\hline Tet-int & $\begin{array}{l}\text { F: CGGATAGATAAAGTACGATA } \\
\text { R: TCACGTCTTTTTTCTGACAT }\end{array}$ & 52 & 2659 & {$[32]$} \\
\hline & $\begin{array}{l}\text { tetM1-F: GAACTCGAACAAGAGGAAAGC } \\
\text { tetM1-R: ATG GAAGCCCAGAAAGGAT }\end{array}$ & 60 & 740 & {$[32]$} \\
\hline $\operatorname{tet}(\mathrm{M})$ & $\begin{array}{l}\text { tetM2-F: GGTGAACATCATAGACACGC } \\
\text { tetM2-R: CTTGTTCGAGTTCCAATGC }\end{array}$ & 58 & 401 & {$[33]$} \\
\hline & $\begin{array}{l}\text { tetL1-F: GTMGTTGCGCGCTATATTCC } \\
\text { tetL1-R: GTGAAMGRWAGCCCACCTAA }\end{array}$ & 55 & 696 & {$[31]$} \\
\hline $\operatorname{tet}(\mathrm{L})$ & $\begin{array}{l}\text { tetL2-F: GTTTCGGGTCGGTAATTGGG } \\
\text { tetL2-R: GCTATCATTCCACCAATCGC }\end{array}$ & 45 & 220 & {$[28]$} \\
\hline $\operatorname{tet}(\mathrm{K})$ & $\begin{array}{l}\text { tetK1-F: TTATGGTGGTTGTAGCTAGAAA } \\
\text { tetK1-R: AAAGGGTTAGAAACTCTTGAAA }\end{array}$ & 55 & 348 & {$[31]$} \\
\hline $\operatorname{tet}(\mathrm{K})$ & $\begin{array}{l}\text { tetK2-F: GTAGCGACAATAGGTAATAG } \\
\text { tetK2-R: GCAACTTCTTCTTCAGAAAG }\end{array}$ & 46 & 278 & {$[28]$} \\
\hline $\operatorname{tet}(\mathrm{S})$ & $\begin{array}{l}\text { F: GGAGTACAGTCACAAACTCG } \\
\text { R: GGATATAAGGAGCAACTTTG }\end{array}$ & 55 & 335 & {$[28]$} \\
\hline $\operatorname{tet}(\mathrm{W})$ & $\begin{array}{l}\text { F: GAGAGCCTGCTATATGCCAGC } \\
\text { R: GGGCGTATCCACAATGTTAAC }\end{array}$ & 55 & 168 & {$[28]$} \\
\hline $16 \mathrm{~S}$ rRNA & $\begin{array}{l}\text { 27F: GAGTTTGATCCTGGCTCAG } \\
\text { 1392R: ACGGTTACCTTGTTACGACTT }\end{array}$ & 51 & 1400 & {$[34]$} \\
\hline
\end{tabular}

11-20, and susceptible (S) at $\geq 21$; bacteria were considered resistant $(\mathrm{R})$ to tetracycline $(30 \mu \mathrm{g} / \mathrm{disc})$ when the zone of inhibition $(\mathrm{mm})$ was $\leq 16$, moderately susceptible (MS) at $17-21$, and susceptible (S) at $\geq 22$.

The MIC for antibiotics was determined by the broth microdilution method in the MRS broth in 96-well nontreated cell culture plates (Eppendorf). Tetracycline (SigmaAldrich) and erythromycin (Sigma-Aldrich) were tested in the concentration range of $0.12-256 \mu \mathrm{g} / \mathrm{ml}$ obtained after a series of twofold dilutions in the MRS broth. Wells were inoculated with $200 \mu \mathrm{l}$ of the bacterial culture $(3 \times$ $10^{7} \mathrm{CFU} / \mathrm{ml}$ ) and incubated at $37^{\circ} \mathrm{C}$. The MIC was read after $48 \mathrm{~h}$ of incubation as the lowest concentration of an antibiotic at which visible growth was inhibited. According to the microbiological breakpoints suggested for L. fermentum by EFSA [11], strains with MICs higher than $1 \mu \mathrm{g} / \mathrm{ml}$ for erythromycin and $8 \mu \mathrm{g} / \mathrm{ml}$ for tetracycline were considered resistant.

2.4. DNA Preparation and Manipulations. Bacteria were cultivated overnight at $37^{\circ} \mathrm{C}$ in $30 \mathrm{ml}$ of the MRS broth. The cells were harvested by centrifugation ( $5 \mathrm{~min}, 13000 \mathrm{RPM}$ ) and then resuspended in $3 \mathrm{ml}$ of the lysis buffer $(50 \mathrm{mM}$
Tris- $\mathrm{HCl}$ and $3 \mathrm{mg} / \mathrm{ml}$ lysozyme, $\mathrm{pH} 8.0$ ). The resuspended pellet was incubated $3 \mathrm{~h}$ at $37^{\circ} \mathrm{C}$ with shaking. After this step, $100 \mu \mathrm{l}$ of sodium dodecyl sulfate (SDS; $10 \%$, w/v) wad added, and the sample was gently inverted for cell disruption. $500 \mu \mathrm{l}$ of phenol : chloroform $(1: 1, \mathrm{v} / \mathrm{v})$ was added. After a centrifugation step (5 min, 13000 RPM, room temperature), the clear supernatant was transferred to a new tube. The DNA was precipitated with $500 \mu \mathrm{l}$ of cold isopropanol, and the DNA was taken out with a plastic tip. The DNA was washed with ethanol $96 \%(\mathrm{w} / \mathrm{v})$, and after it has been dried, it was diluted in $100 \mu \mathrm{l}$ of distilled water. All the DNA samples were stored at $-20^{\circ} \mathrm{C}$.

Plasmid DNA was obtained using GeneJET Plasmid Miniprep Kit (Thermo Scientific), according to the manufacturer's instructions.

2.5. PCR Detection of Genes. The presence of erythromycin and tetracycline resistance genes was determined by PCR amplification using the primers listed in Table 1. The presence of the transposon Tn916 was detected by amplification of the integrase-encoding gene (Int) and examining the interregion between tet $(\mathrm{M})$ and Int genes with the primer Tet-int described in Table 1. 
The PCR reaction was carried out in a total volume of $25 \mu \mathrm{l}$ containing DNA template, $10 \mathrm{pmol}$ of each primer (Table 1), $1 \mathrm{U}$ Taq DNA polymerase, each of four dNTPs at a concentration of $200 \mu \mathrm{M}$, and PCR buffer containing Tris$\mathrm{HCl}, \mathrm{KCl},\left(\mathrm{NH}_{4}\right)_{2} \mathrm{SO}_{4}, \mathrm{MgSO}_{4}$, and Triton X-100. The amplification program was as follows: initial denaturation at $95^{\circ} \mathrm{C}$ for $4 \mathrm{~min}, 35$ cycles at $94^{\circ} \mathrm{C}$ for $30 \mathrm{~s}, 46-60^{\circ} \mathrm{C}$ (according to the annealing temperature for the individual primers; Table 1) for $30 \mathrm{~s}$, and $72^{\circ} \mathrm{C}$ for $1.5 \mathrm{~min}$, and a final extension step at $72^{\circ} \mathrm{C}$ for $7 \mathrm{~min}$. Positive and negative controls from our lab were used for all PCR reactions. PCR products $(5 \mu \mathrm{l})$ were separated by electrophoresis on a $1 \%$ agarose gel, which was stained with Midori Green DNA Stain (Nippon Genetics Europe, Germany).

2.6. Filter Mating Experiments. Transferability of antibiotic resistance from lactobacilli was examined by filter mating, as described in [24], on a number of Gram-positive (Staphylococcus aureus subsp. aureus ATCC ${ }^{\circledR} 29213^{\mathrm{TM}}$, Staphylococcus haemolyticus, Staphylococcus epidermidis (clinical isolates), and Listeria monocytogenes $88 \mathrm{~K}$ (a gift from Dr. Alexey Vasilchenko, Orenburg State University)) and Gramnegative (Acinetobacter baumannii, Citrobacter freundii, and Escherichia coli (clinical isolates)) bacteria. Clinical isolates of S. haemolyticus, S. epidermidis, and E. coli were obtained from the Kazan Institute of Epidemiology and Microbiology (Kazan, Russia). Clinical isolates of A. baumannii and $C$. freundii were obtained from the Institute of Medical Microbiology (Giessen, Germany). Cultures of pathogens were incubated in the Luria-Bertani (LB) medium. Antibiotic resistance profiles of recipient strains were characterized by determination of MICs, as described above. The lack of erythromycin and tetracycline resistance genes was proved by PCR, as indicated earlier. S. haemolyticus was sensitive to both erythromycin and tetracycline but carried the tet $(\mathrm{K})$ gene and therefore was used as the recipient strain for erythromycin resistance genes. Other tested strains were either resistant to erythromycin (all Gram-negative strains) or possessed a silent erm(B) gene (S. aureus, S. epidermidis, and $L$. monocytogenes). As they were sensitive to tetracycline and lacked tet genes, they were used as recipient strains for tetracycline resistance genes. Chloramphenicol $(40 \mu \mathrm{g} / \mathrm{ml})$ was used as a selective antibiotic marker for transconjugants of S. epidermidis, S. haemolyticus, and A. baumannii, rifampicin $(2.5 \mu \mathrm{g} / \mathrm{ml})$ for $S$. aureus, L. monocytogenes, and $E$. coli, and ampicillin $(40 \mu \mathrm{g} / \mathrm{ml})$ for C. freundii. These concentrations were sufficient to completely inhibit growth of Lactobacillus, whereas recipient bacteria were unaffected.

For filter mating experiments, the MRS broth and LB broth were inoculated $(1: 100)$ with overnight grown donor L. fermentum cultures and recipient pathogen cultures, correspondingly, and incubated at $37^{\circ} \mathrm{C}$ for approx. $4 \mathrm{~h}$ to the mid-exponential phase of growth. One $\mathrm{ml}$ of each culture was mixed and filtered through a sterile $0.45 \mu \mathrm{m}$ pore-size nitrocellulose membrane filter (Millipore, USA). After that, sterile peptone physiological saline (PPS) solution $(8.5 \mathrm{~g} / \mathrm{l}$ $\mathrm{NaCl}$ and $1 \mathrm{~g} / \mathrm{l}$ bacteriological peptone) was passed through the filter to trap the cells more tightly into the membrane.
The filters were incubated overnight on the LB agar at $37^{\circ} \mathrm{C}$. The bacteria were washed from the filters with $2 \mathrm{ml}$ PPS. Dilutions of the mating mixtures were spread onto LB agar plates containing $10 \mu \mathrm{g} / \mathrm{ml}$ tetracycline or erythromycin (Sigma-Aldrich) and selective antibiotic (chloramphenicol, rifampicin, or ampicillin, all from Sigma-Aldrich) (double selective medium), agar plates containing $10 \mu \mathrm{g} / \mathrm{ml}$ tetracycline or erythromycin (Sigma-Aldrich) or selective antibiotic (single selective medium), and nonselective medium without antibiotics. Control cultures of donor and recipient strains were also individually plated on three types of agar plates. Plates were incubated at $37^{\circ} \mathrm{C}$ for $24-48 \mathrm{~h}$.

\section{Results and Discussion}

3.1. Isolation and Identification of L. fermentum Strains. In our previous work, among 15 Lactobacillus strains isolated from feces of healthy volunteers (unpublished data) and 19 Lactobacillus strains isolated from commercial dairy products and probiotics [27], six strains were shown to be resistant to either erythromycin or tetracycline by the disc diffusion method. Resistance to these two antibiotics is considered the most threatening one in probiotics because it is often acquired and potentially transferable [16, 17]. Therefore, these six Lactobacillus strains were used in this study to comprehensively characterize their erythromycin or tetracycline resistance profiles and evaluate the transferability of corresponding resistance genes to other bacteria. All tested strains were putatively assigned to L. fermentum species by MALDI Biotyper as sample mass spectra shared the maximum similarity with the reference mass spectrum of L. fermentum from MALDI Biotyper software (score values ranged between 2.019 and 2.083). This finding was verified by $16 \mathrm{~S}$ rRNA gene analysis after we determined that sample 16 S rDNA sequences had a similarity score of $\geq 99 \%$ with that of reference sequences in the NCBI database classified as L. fermentum.

3.2. Phenotypic Profile of Antimicrobial Resistance. Phenotypic profile of L. fermentum resistance to erythromycin and tetracycline is presented in Table 2. All strains tested in this study were susceptible or moderately susceptible to erythromycin by disc diffusion, except for the strain 5-1, which was resistant. With MICs between 0.25 and $1 \mu \mathrm{g} / \mathrm{ml}$, all strains were considered susceptible to erythromycin based on the MIC breakpoints established by EFSA [11]. Five tested L. fermentum isolates showed resistance to tetracycline, whereas the strain 5-1 was moderately susceptible. In full concordance with the results of the disc diffusion method, these five isolates of L. fermentum showed high MICs of $16-64 \mu \mathrm{g} / \mathrm{ml}$ for tetracycline and thus were assigned as resistant to tetracycline according to [11]. Tetracycline resistance common among the human fecal isolates may be explained by the intensive use of tetracyclines, alone or in combination, in medicine for prophylaxis or therapy and in consumed food, which could provide the selective pressure needed for antibiotic-resistant bacteria to develop and spread. The phenotypic profile of antimicrobial 


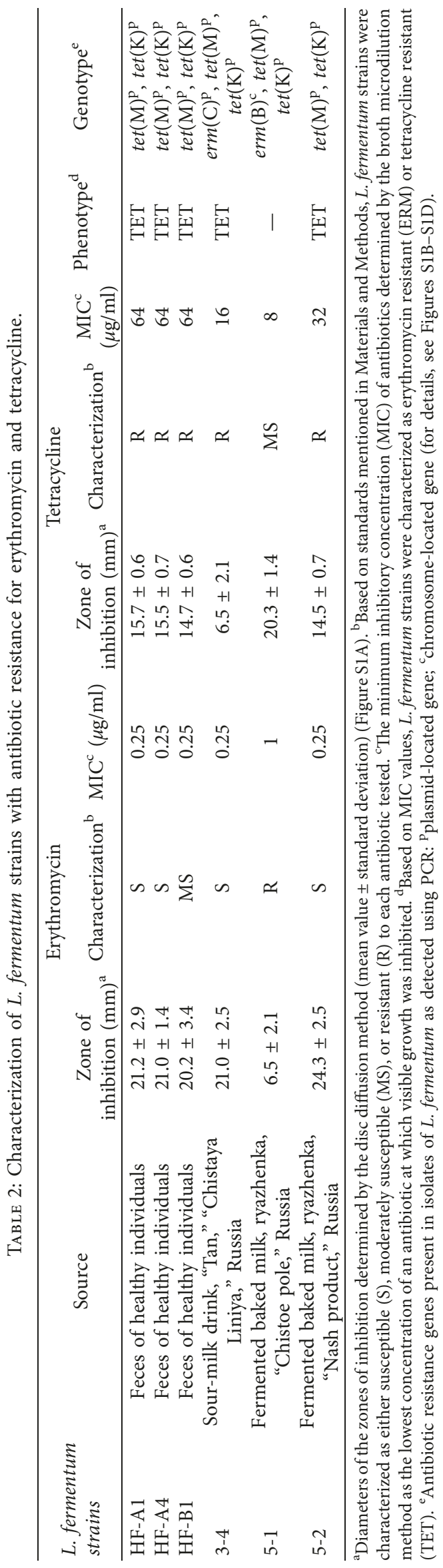


resistance characterized by disc diffusion mainly coincided with observed MICs, except for the strain L. fermentum 5-1, which was resistant to erythromycin in the disc diffusion method, but ultimately was considered nonresistant according to the MIC value.

Thus, phenotypic assays showed that L. fermentum strains HF-A1, HF-A4, HF-B1, 3-4, and 5-2 possess tetracycline resistance which is potentially transferable.

3.3. Antibiotic Resistance Genes. Antibiotic resistance genes were detected by PCR, and the results are presented in Table 2. All the strains were tested for the presence of erythromycin resistance genes $\mathrm{erm}(\mathrm{A}), \mathrm{erm}(\mathrm{B}), \mathrm{erm}(\mathrm{C}), \mathrm{erm}$ (T), and mef(A). Only L. fermentum 5-1 was positive for the erm(B) gene, giving a $425 \mathrm{bp}$ band, corresponding to its resistance phenotype in the disc diffusion assay (Figure S1B, lane 2). The erm(B) gene, which encodes an rRNA methylase acting on the $23 \mathrm{~S}$ ribosomal subunit, is the most frequently found one of all erythromycin resistance genes in Lactobacillus species [15]. According to PCR results, the erm(B) gene was attributed to chromosomal DNA in L. fermentum 5-1 and thus is not likely to be transferable. However, acquired resistance to erythromycin because of erm(B) has often been reported in lactobacilli from different sources $[9,18,20,21,23,35]$. The erythromycin resistance gene erm (C) was found in plasmid DNA from L. fermentum 3-4 (Figure S1B, lane 3), and to our knowledge, this gene has not been described previously from that particular species. Its lower prevalence among lactobacilli is consistent with previous reports $[20,35]$. The $\operatorname{erm}(\mathrm{C})$ gene has only been detected in few $L$. plantarum strains from fermented dry sausages [36] and several chicken isolates of the species $L$. salivarius, $L$. agilis, L. crispatus, $L$. reuteri, and $L$. saerimneri [37]. Other erythromycin resistance determinants (erm(T) and $m e f(\mathrm{~A}))$ were not detected in any strain.

In this study, we also tested the presence of tetracycline resistance genes tet $(\mathrm{K})$, tet $(\mathrm{M})$, tet $(\mathrm{W})$, tet $(\mathrm{S})$, and tet $(\mathrm{L})$. The tet $(\mathrm{K})$ and tet $(\mathrm{M})$ genes were found in plasmid DNA of all the tested strains (Figures S1C and S1D). These determinants have different modes of action: tet $(\mathrm{K})$ encodes efflux pumps, whereas tet $(\mathrm{M})$ offers ribosomal protection [16]. The simultaneous occurrence of $\operatorname{tet}(\mathrm{K})$ and $\operatorname{tet}(\mathrm{M})$ genes is in agreement with reports of other lactobacilli containing multiple tet genes [18, 20, 37-39]. Genetic location of the tet (K) gene on small multicopy plasmids and tet(M) on conjugative transposons (Tn916-Tn1545 family) promotes the spread of these determinants [16]. Yet in this study, we have shown that all the tested $L$. fermentum strains lack the conjugative transposon Tn916, carrying the tet(M) gene and capable of horizontal, interspecies transfer. No amplicons were yielded when primer pairs specific for the int gene, encoding the integrase protein that allows mobilization of Tn916, and for the intervening region between the tet(M) and int sequences, were used (data not shown). We did not find any of tet(W), tet(S), and tet(L) genes in this study.

Results of PCR screening for antibiotic resistance determinants in the L. fermentum strains were only partly consistent with those of phenotypic assays. Detection of tet genes in the strains HF-A1, HF-A4, HF-B1, 3-4, and 5-2 was in agreement with their resistance phenotypes. L. fermentum 5-1 sensitive to tetracycline was discovered to carry silent genes tet $(\mathrm{K})$ and tet $(\mathrm{M})$, and L. fermentum 3-4 sensitive to erythromycin was positive for erm(C). Detection of erm(B) in L. fermentum 5-1 was in agreement with its erythromycin resistant phenotype shown in the disc diffusion assay but was in contradiction with the results of MIC determination. These controversial results can be explained by dependence of susceptibility results on the method for antibiotic susceptibility assessment. It was shown that an increased inoculum size and an extended incubation time resulted in elevated antibiotic MICs for some species [14].

3.4. Transfer of Antibiotic Resistance Genes. We studied the transfer of tetracycline resistance genes by filter mating from six L. fermentum strains positive for tet $(\mathrm{K})$ and tet $(\mathrm{M})$ to a number of Gram-positive and Gram-negative bacteriaStaphylococcus aureus, Staphylococcus epidermidis, Listeria monocytogenes, Acinetobacter baumannii, Citrobacter freundii, and Escherichia coli. Also, L. fermentum 5-1 carrying the erm(B) gene and L. fermentum 3-4 carrying the erm(C) gene were used as donors, while Staphylococcus haemolyticus served as a recipient for erythromycin resistance genes. The recipient strains were chosen experimentally and met two criteria necessary for counterselection of transconjugants: (i) lack of resistance to erythromycin or tetracycline both in phenotypes and genotypes and (ii) presence of resistance to antibiotic active against tested Lactobacillus strains. Besides, these bacteria are members of the human gastrointestinal microbiota [40]. Coagulase-negative staphylococci S. epidermidis and S. haemolyticus usually colonize normal human skin but also may be isolated from the human gastrointestinal tract. Isolates from the intestinal tracts have been found to express virulence factors indicating their pathogenicity potentials [41].

The results showed that erythromycin and tetracycline resistance genes from tested L. fermentum strains cannot be transferred to the other bacteria used in this study via conjugation. No bacterial growth was observed in plates with the double selective medium, thus indicating that none of the recipient cells harbored erythromycin or tetracycline resistance (data not shown).

Lactobacilli and Gram-negative bacteria is an uncommon pair in studying the transferability of antibiotic resistance determinants. To date, there is only one report on conjugative transfer of antibiotic resistance genes from $L$. fermentum to other bacteria. The $\operatorname{erm}(\mathrm{B})$ gene from $L$. fermentum NWL24 was successfully transferred to Enterococcus faecalis 181 by filter mating [18]. However, it was demonstrated that gene transfer via conjugation can take place from Gram-positive to Gram-negative bacteria, and vice versa $[42,43]$. The streptococcal conjugative transposon Tn916 was shown to be able to cross the barrier between a variety of Gram-positive and Gram-negative bacteria, with subsequent expression in the new host [42]. Thus, absence of transconjugants in performed filter mating experiments coincides with the lack of Tn916 in tested L. fermentum strains. 
The disability to transfer genes for antibiotic resistance is considered an important parameter for the selection of the LAB strains for the food industry and probiotics [15]. This property is equally important for lactobacilli of normal human microbiota in order to avoid spread of resistance determinants among different species, including potential and obligate pathogens, in habitats with close association of densely packed microorganisms such as the intestine of humans. In all tested L. fermentum strains, tet(K) and tet(M) genes were shown to be located in plasmids and thus are likely to be acquired. Three L. fermentum strains (3-4, 5-1, and 5-2) isolated from dairy products represent a serious safety issue because of their tetracycline-resistant phenotype (strains 3-4 and 5-2) and simultaneous presence of tetracycline resistance genes tet $(\mathrm{K})$ and tet $(\mathrm{M})$ (all strains) along with erythromycin resistance genes erm(B) (strain 5-1) and erm (C) (strain 3-4). In this work, we have shown that all tested lactobacilli lack conjugative transposon Tn916 and are not able to transfer tetracycline resistance genes to $S$. aureus, S. epidermidis, L. monocytogenes, A. baumannii, C. freundii, and $E$. coli by filter mating. Mating of L. fermentum 5-1 carrying the $\operatorname{erm}(\mathrm{B})$ gene and L. fermentum 3-4 carrying the erm(C) gene did not yield transconjugants with $S$. haemolyticus as well. These findings reduce the likelihood of the impact of tested lactobacilli to the spread of erythromycin and tetracycline resistance in the human microbiome and favor their safe status but still do not establish their complete safety. Our results highlight the need to include screening of antibiotic resistance into the current practices of safety evaluation mandatory before application of Lactobacillus strains as starter cultures or as probiotics.

\section{Data Availability}

The data used to support the findings of this study are included within the article.

\section{Conflicts of Interest}

The authors declare that there are no conflicts of interest regarding the publication of this paper.

\section{Authors' Contributions}

Elizaveta Anisimova carried out the study and drafted the manuscript. Dina Yarullina designed the experiments, reviewed the manuscript, and supervised the work. All authors read and approved the final manuscript.

\section{Acknowledgments}

This work was supported by the Program of Competitive Growth of Kazan Federal University, RFBR grant no. 18-3400268 and partially by RFBR grant no. 17-00-00456 (strain isolation). The research was performed by using the equipment of the Interdisciplinary Center for Collective Use of Kazan Federal University for cellular, genomic, and postgenomic research in Volga region.

\section{Supplementary Materials}

Figure S1: phenotypic (A) and genotypic (B, C, and D) erythromycin and tetracycline resistance testing of $L$. fermentum. (A) Inhibition halos obtained by the agar disc diffusion method for L. fermentum 5-1 (1), L. fermentum HF-A1 (2), L. fermentum HF-A4 (3), L. fermentum HF-B1 (4), L. fermentum 3-4 (5), and L. fermentum 5-2 (6). PCR products of erythromycin (B) and tetracycline (C and D) resistance genes. (B) The PCR products amplified with erm (B) 1 primer pair in plasmid DNA (lane 1) and total DNA (lane 2) of L. fermentum 5-1 and with $\operatorname{erm}(\mathrm{C})$ primer pair in plasmid DNA (lane 3) and total DNA (lane 4) of L. fermentum 3-4. The PCR products amplified with tet $(\mathrm{K}) 2(\mathrm{C})$ and tet(M)1 (D) primer pairs in plasmid DNA of L. fermentum HF-A1 (lane 1), L. fermentum HF-B1 (lane 2), L. fermentum HF-A4 (lane 3), L. fermentum 5-1 (lane 4), L. fermentum 3-4 (lane 5), and L. fermentum 5-2 (lane 6). Lane M, 1 kb DNA ladder. (Supplementary Materials)

\section{References}

[1] S. Kaewnopparat, N. Dangmanee, N. Kaewnopparat, T. Srichana, M. Chulasiri, and S. Settharaksa, "In vitro probiotic properties of Lactobacillus fermentum SK5 isolated from vagina of a healthy woman,” Anaerobe, vol. 22, pp. 6-13, 2013.

[2] V. Liévin-Le Moal and A. L. Servin, "Anti-infective activities of Lactobacillus strains in the human intestinal microbiota: from probiotics to gastrointestinal anti-infectious biotherapeutic agents," Clinical Microbiology Reviews, vol. 27, no. 2, pp. 167-199, 2014.

[3] C. L. Ramos, L. Thorsen, R. F. Schwan, and L. Jespersen, "Strain-specific probiotics properties of Lactobacillus fermentum, Lactobacillus plantarum and Lactobacillus brevis isolates from Brazilian food products," Food Microbiology, vol. 36, no. 1, pp. 22-29, 2013.

[4] T. A. Melo, T. F. Dos Santos, L. R. Pereira, H. M. Passos, R. P. Rezende, and C. C. Romano, "Functional profile evaluation of Lactobacillus fermentum TCUESC01: a new potential probiotic strain isolated during cocoa fermentation," BioMed Research International, vol. 2017, Article ID 5165916, 7 pages, 2017.

[5] G. Giraffa, N. Chanishvili, and Y. Widyastuti, "Importance of lactobacilli in food and feed biotechnology," Research in Microbiology, vol. 161, no. 6, pp. 480-487, 2010.

[6] I. V. Belova, A. G. Tochilina, I. V. Solovyeva et al., "Lactobacillus fermentum 90 TC-4 taxonomic status confirmation using whole genome sequencing and MALDI TOF mass spectrum," Russian Journal of Genetics, vol. 52, no. 9, pp. 907-913, 2016.

[7] EFSA Panel on Biological Hazards (BIOHAZ), A. Ricci, A. Allende et al., "Update of the list of QPS-recommended biological agents intentionally added to food or feed as notified to EFSA 7: suitability of taxonomic units notified to EFSA until September 2017," EFSA Journal, vol. 16, no. 1, pp. 5131-5143, 2018.

[8] M. Zheng, R. Zhang, X. Tian, X. Zhou, X. Pan, and A. Wong, "Assessing the risk of probiotic dietary supplements in the context of antibiotic resistance," Frontiers in Microbiology, vol. 8, p. 908, 2017.

[9] S. Mathur and R. Singh, "Antibiotic resistance in food lactic acid bacteria-a review," International Journal of Food Microbiology, vol. 105, no. 3, pp. 281-295, 2005. 
[10] P. Sharma, S. K. Tomar, P. Goswami, V. Sangwan, and R. Singh, "Antibiotic resistance among commercially available probiotics," Food Research International, vol. 57, pp. 176-195, 2014.

[11] EFSA, "Technical guidance prepared by the panel on additives and Products or substances used in animal feed (FEEDAP) on the update of the criteria used in the assessment of bacterial resistance to antibiotics of human or veterinary importance (question no. EFSA-Q-2008-004)," EFSA Journal, vol. 732, pp. 1-15, 2008.

[12] G. Huys, K. D’Haene, and J. Swings, "Influence of the culture medium on antibiotic susceptibility testing of food-associated lactic acid bacteria with the agar overlay disc diffusion method," Letters in Applied Microbiology, vol. 34, no. 6, pp. 402-406, 2002.

[13] M. Danielsen and A. Wind, "Susceptibility of Lactobacillus spp. to antimicrobial agents," International Journal of Food Microbiology, vol. 82, no. 1, pp. 1-11, 2003.

[14] M. Egervärn, H. Lindmark, S. Roos, G. Huys, and S. Lindgren, "Effects of inoculum size and incubation time on broth microdilution susceptibility testing of lactic acid bacteria," Antimicrobial Agents and Chemotherapy, vol. 51, no. 1, pp. 394-396, 2007.

[15] M. Gueimonde, B. Sánchez, C. G. de los Reyes-Gavilán, and A. Margolles, "Antibiotic resistance in probiotic bacteria," Frontiers in Microbiology, vol. 4, p. 202, 2013.

[16] M. C. Roberts, "Update on acquired tetracycline resistance genes," FEMS Microbiology Letters, vol. 245, no. 2, pp. 195203, 2005.

[17] M. C. Roberts, "Update on macrolide-lincosamidestreptogramin, ketolide, and oxazolidinone resistance genes," FEMS Microbiology Letters, vol. 282, no. 2, pp. 147159,2008

[18] M. Nawaz, J. Wang, A. Zhou et al., "Characterization and transfer of antibiotic resistance in lactic acid bacteria from fermented food products," Current Microbiology, vol. 62, no. 3, pp. 1081-1089, 2011.

[19] L. Pan, X. Hu, and X. Wang, "Assessment of antibiotic resistance of lactic acid bacteria in Chinese fermented foods," Food Control, vol. 22, no. 8, pp. 1316-1321, 2011.

[20] S. C. R. Thumu and P. M. Halami, "Presence of erythromycin and tetracycline resistance genes in lactic acid bacteria from fermented foods of Indian origin," Antonie van Leeuwenhoek, vol. 102, no. 4, pp. 541-551, 2012.

[21] K. Y. Gfeller, M. Roth, L. Meile, and M. Teuber, "Sequence and genetic organization of the 19.3-kb erythromycin and dalfopristin-resistance plasmid pLME300 from Lactobacillus fermentum ROT1," Plasmid, vol. 50, no. 3, pp. 190201, 2003.

[22] H. Ishiwa and S. Iwata, "Drug resistance plasmids in Lactobacillus fermentum," Journal of General and Applied Microbiology, vol. 26, no. 1, pp. 71-74, 1979.

[23] M. Fons, T. Hégé, M. Ladiré, P. Raibaud, R. Ducluzeau, and E. Maguin, "Isolation and characterization of a plasmid from Lactobacillus fermentum conferring erythromycin resistance," Plasmid, vol. 37, no. 3, pp. 199-203, 1997.

[24] D. Gevers, G. Huys, and J. Swings, "In vitro conjugal transfer of tetracycline resistance from Lactobacillus isolates to other Gram-positive bacteria," FEMS Microbiology Letters, vol. 225, no. 1, pp. 125-130, 2003.

[25] L. Jacobsen, A. Wilcks, K. Hammer, G. Huys, D. Gevers, and S. R. Andersen, "Horizontal transfer of tet(M) and erm(B) resistance plasmids from food strains of Lactobacillus plantarum to Enterococcus faecalis $\mathrm{JH} 2-2$ in the gastrointestinal tract of gnotobiotic rats," FEMS Microbiology Ecology, vol. 59, no. 1, pp. 158-166, 2007.

[26] L. I. I. Ouoba, V. Lei, and L. B. Jensen, "Resistance of potential probiotic lactic acid bacteria and bifidobacteria of African and European origin to antimicrobials: determination and transferability of the resistance genes to other bacteria," International Journal of Food Microbiology, vol. 121, no. 2, pp. 217-224, 2008.

[27] N. L. Bruslik, D. R. Akhatova, A. A. Toimentseva, S. R. Abdulkhakov, O. N. Ilyinskaya, and D. R. Yarullina, "Estimation of probiotic lactobacilli drug resistance," Antibiotics and chemoterapy, vol. 60, no. 3-4, pp. 6-13, 2015.

[28] M. Egervärn, S. Roos, and H. Lindmark, "Identification and characterization of antibiotic resistance genes in Lactobacillus reuteri and Lactobacillus plantarum," Journal of Applied Microbiology, vol. 107, no. 5, pp. 1658-1668, 2009.

[29] J. Sutcliffe, T. Grebe, A. Tait-Kamradt, and L. Wondrack, "Detection of erythromycin-resistant determinants by PCR," Antimicrobial Agents and Chemotherapy, vol. 40, no. 11, pp. 2562-2566, 1996.

[30] C. Liu, Z. Y. Zhang, K. Dong, J. P. Yuan, and X. K. Guop, "Antibiotic resistance of probiotic strains of lactic acid bacteria isolated from marketed foods and drugs," Biomedical and Environmental Sciences, vol. 22, no. 5, pp. 401-412, 2009.

[31] D. Gevers, M. Danielsen, G. Huys, and J. Swings, "Molecular characterization of tet $(\mathrm{M})$ genes in Lactobacillus isolates from different types of fermented dry sausage," Applied and Environmental Microbiology, vol. 69, no. 2, pp. 1270-1275, 2003.

[32] C. Devirgiliis, D. Coppola, S. Barile, B. Colonna, and G. Perozzi, "Characterization of the Tn916 conjugative transposon in a food-borne strain of Lactobacillus paracasei," Applied and Environmental Microbiology, vol. 75, no. 12, pp. 3866-3871, 2009.

[33] G. Werner, R. J. L. Willems, B. Hildebrandt, I. Klare, and W. Witte, "Influence of transferable genetic determinants on the outcome of typing methods commonly used for Enterococcus faecium," Journal of Clinical Microbiology, vol. 41, no. 4, pp. 1499-1506, 2003.

[34] D. J. Lane, "16S/23S rRNA sequencing," in Nucleic Acid Techniques in Bacterial Systematics, E. Stackebrandt and M. Goodfellow, Eds., pp. 115-175, John Wiley and Sons, New York, NY, USA, 1991.

[35] A. S. Hummel, C. Hertel, W. H. Holzapfel, and C. M. A. P Franz, "Antibiotic resistances of starter and probiotic strains of lactic acid bacteria," Applied and Environmental Microbiology, vol. 73, no. 3, pp. 730-739, 2007.

[36] D. Zonenschain, A. Rebecchi, and L. Morelli, "Erythromycinand tetracycline-resistant lactobacilli in Italian fermented dry sausages," Journal of Applied Microbiology, vol. 107, no. 5, pp. 1559-1568, 2009.

[37] M. Dec, R. Urban-Chmiel, D. Stępień-Pyśniak, and A. Wernicki, "Assessment of antibiotic susceptibility in Lactobacillus isolates from chickens," Gut Pathogens, vol. 9, no. 1, p. 54, 2017.

[38] E. Songisepp, P. Hütt, M. Rätsep et al., "Safety of a probiotic cheese containing Lactobacillus plantarum Tensia according to a variety of health indices in different age groups," Journal of Dairy Science, vol. 95, no. 10, pp. 5495-5509, 2012.

[39] M. S. Ammor, M. Gueimonde, M. Danielsen et al., "Two different tetracycline resistance mechanisms, plasmid-carried tet $(\mathrm{L})$ and chromosomally located transposon-associated tet (M), coexist in Lactobacillus sakei Rits 9," Applied and Environmental Microbiology, vol. 74, no. 5, pp. 1394-1401, 2008. 
[40] M. Rajilić-Stojanović and W. M. de Vos, "The first 1000 cultured species of the human gastrointestinal microbiota," FEMS Microbiology Reviews, vol. 38, no. 5, pp. 996-1047, 2014.

[41] E. O. Akinkunmi and A. Lamikanra, "Phenotypic determination of some virulence factors in staphylococci isolated from faecal samples of Nigerian children," African Journal of Biomedical Research, vol. 15, no. 2, pp. 123-128, 2012.

[42] J. Bertram, M. Stratz, and P. Durre, "Natural transfer of conjugative transposon Tn916 between gram-positive and gram-negative bacteria," Journal of Bacteriology, vol. 173, no. 2, pp. 443-448, 1991.

[43] P. Courvalin, "Transfer of antibiotic resistance genes between gram-positive and gram-negative bacteria," Antimicrobial Agents and Chemotherapy, vol. 38, no. 7, pp. 1447-1451, 1994. 


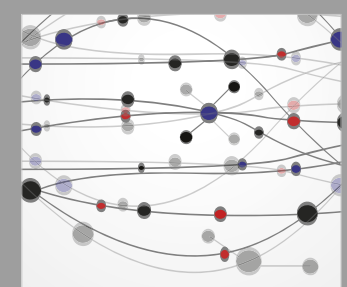

The Scientific World Journal
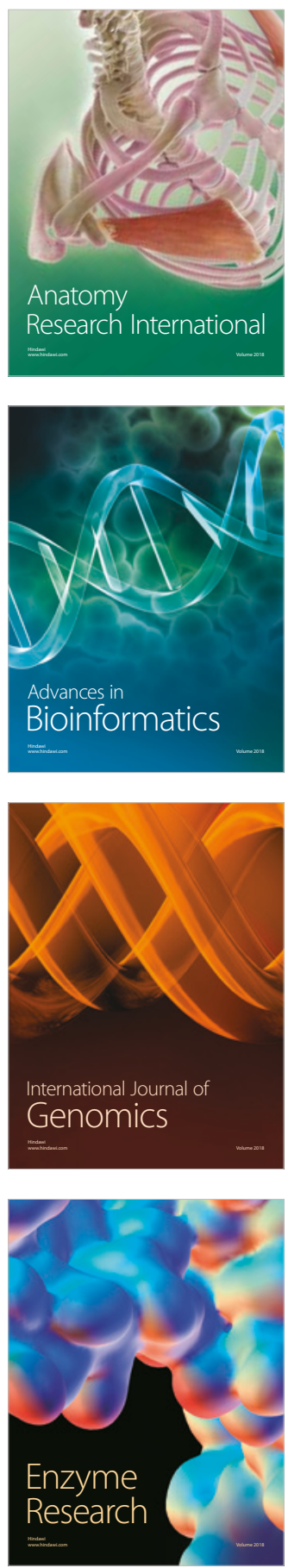
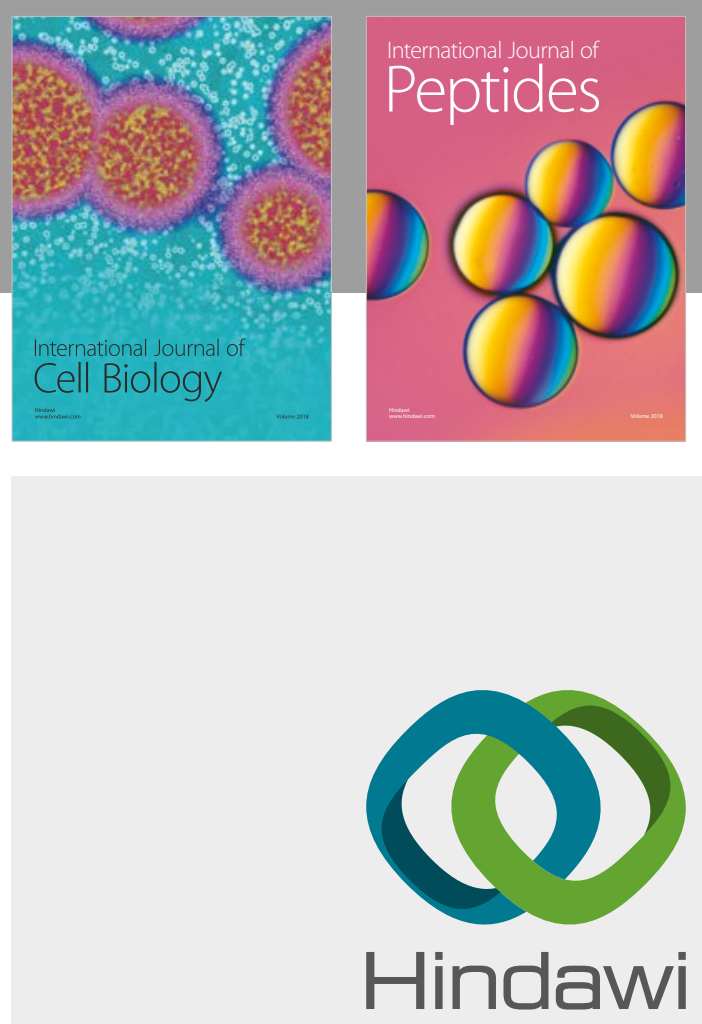

Submit your manuscripts at

www.hindawi.com
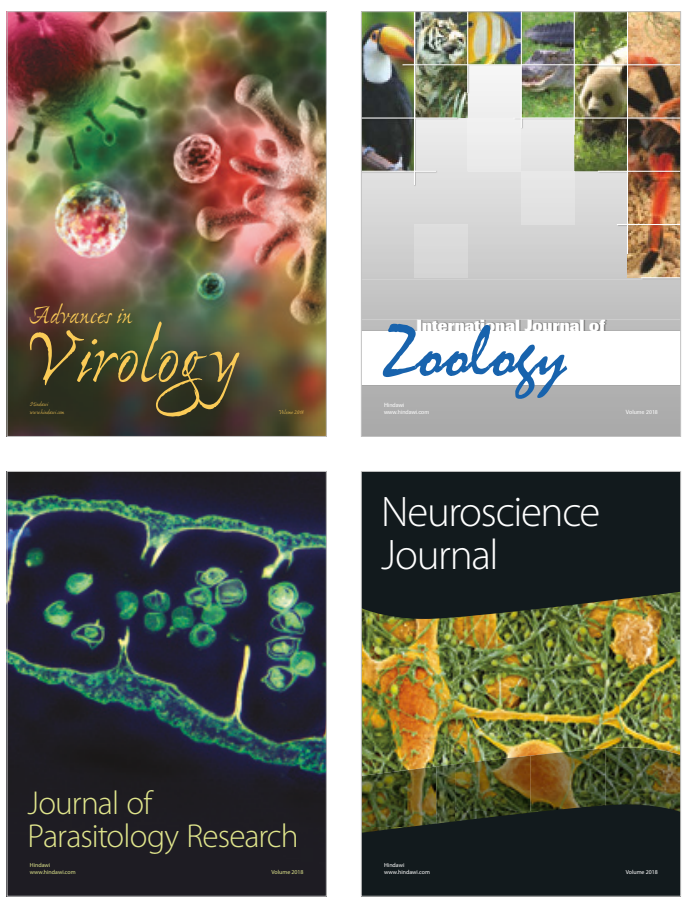
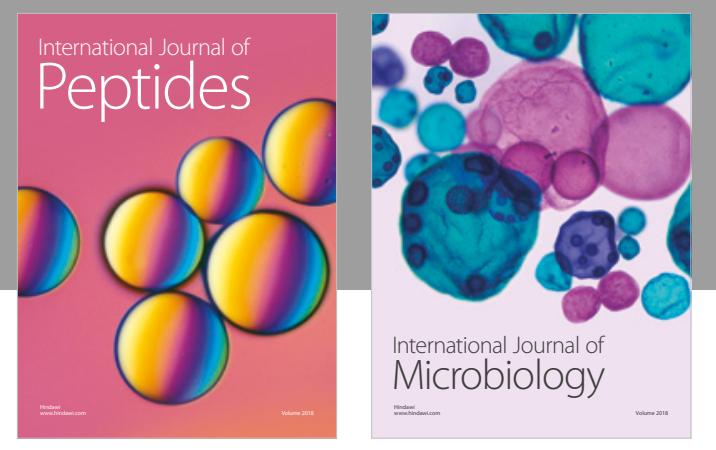

nternational Journal of Microbiology
Journal of
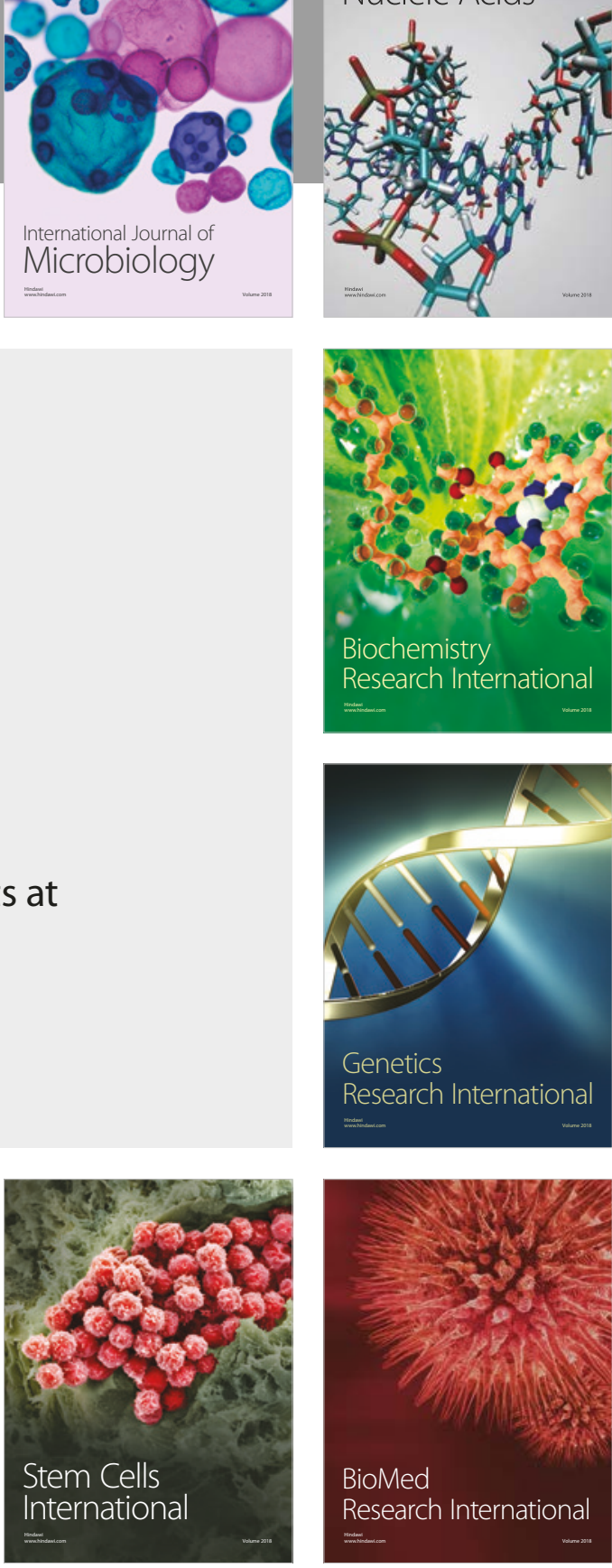
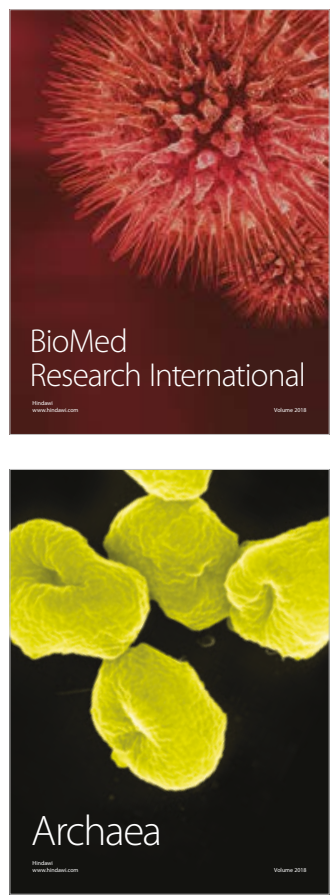